\title{
Globalization - the source of new crises
}

\author{
Aleš $\operatorname{Hes}^{1, *}$ \\ ${ }^{1}$ University of Finance and Administration in Prague, Estonska 500, CZ 101 00, Prague 10, Czech \\ Republic
}

\begin{abstract}
Research background: Globalization not only benefits national and corporate companies, but also brings together a new threat in the form of new, as yet unexplored crises. A company that is economically connected with suppliers of foreign companies may find itself in a very unpleasant situation due to a global pandemic and may not meet its marketing goals. The article analyzes the given fact and looks for real starting points through greater involvement of modern communication technologies. Modern communication technologies can help with the growing negative impacts of global trade on national economies and society. It is possible to prevent conflict situations through communication activities and find compromise solutions to possible crises (COVID '19).

Purpose of the article: Based on analytical reasoning, the article attempts to find real ways to minimize the negative impacts of global trade on the needs and interests of national economies using modern digital communication technologies.

Methods: The main methods used are structured analysis of real facts concerning the effects of globalization on national economic interests, cognitive description of facts, as well as methods of synthesis, logical and deductive procedures to examine communication paths leading to minimizing the effects of globalization on modern society.

Findings \& Value added: The article will present the causes of the selected crisis situation and provide general recommendations for mitigating the negative impacts of global trade on society and national economic interests. Keywords: globalization; corporate enterprises; behavior; communication; crisis; incorporation
\end{abstract}

JEL Classification: $M 21 ; M 31 ; L 21$

*Corresponding author: 26617@mail.vsfs.cz 


\section{Introduction}

Globalization is constantly evolving thanks to a growing group of influential economic players such as Asian countries - China, South Korea, Brazil. This process is related to the development of a consumer postmodern society that is increasing its requirements for its comfortable lifestyle. At the beginning of global trends, when it was mainly a matter of moving production to areas with lower production factors and bringing higher profits to corporate companies, the business and economic structure is currently strongly economically and ownership intertwined, which is reflected in growing dependence on individual articles of the economic and trade network. Global trends have brought some positive benefits to global society, especially in the areas of technology development, digital communication or innovation in production, products, and services. However, they also brought some negative manifestations that did not exist in closed economies. Among the very noticeable negative manifestations of globalization were the loss of social identity, the increase in migration, unexpected turbulent phenomena, and the production of certain risks. There is another very dangerous risk associated with this, resulting from the global interconnection of economies. If there is a crisis (financial, health, pandemic, political) in a certain national economy, the effects can be devastating due to the global connection to other individual economies. Today's modern society has become accustomed to moving in an environment of overproduction and thus also contributes to large overconsumption, causing uncontrolled waste of vital and non-renewable resources. All this has another parallel in the form of a large increase in the influence of the media and modern communication technologies. On the one hand, they inform society about the given phenomena, on the other hand, due to the increase in traceability, they co-create the information or even create it themselves. The extraordinary increase in media influences causes a change in the lifestyle of society, where qualities such as selfishness, ruthlessness, indifference begin to dominate. People live in excessive haste to follow the example of rich and popular people presented by the media and social influences. They do not realize this pernicious social process until the outbreak of a crisis, negatively affecting their needs and interests. By being affected by a shortage in a certain sphere of production or sector, the possibilities, and ways to maintain a standard of living and not fall into the sphere of poverty increase.

\section{Material and methodology}

The main methods that were used in the processing of this issue were structured analyzes and especially the description of facts, as well as methods of synthesis, logical and deduction procedures to properly formulate the sources of possible global crises. The topic is organized according to the logic of facts and through deduction from the analysis of scientific texts and real global phenomena, to formulate, identify and characterize real measures to minimize the impact of crises.

\section{Results and discussion}

In 2020, the world economy began to change significantly. It has entered a deep crisis; which experts say will take longer than expected. The main reason for this situation is the COVID '19 pandemic, which has significantly affected political decisions, economic relations, values and goals of states around the global world. Countries have had to resort to large-scale restrictions on economic activity, even severely restricting entire economic sectors, and strengthening or creating new communication channels that have replaced 
traditional production and business processes. The COVID '19 pandemic has developed the preconditions for large-scale digitization, which has significantly affected the functioning of the global economy. In 2020, according to official EU statistics, GDP fell by $4.8 \%$ and was expected to grow at $4.3-5.3 \%$. Nevertheless, the higher consequences of a pandemic can be considered, which in the long run will trigger a global crisis in the heavy and energy industries. This will also cause an increase in the crisis in the field of small and mediumsized enterprises, which is more than $65 \%$ connected with the activities of large corporate global companies. The entire service sector is one of the sectors that has been hit hard by the pandemic. Thanks to tough measures, it is very unlikely that everything will return to normal in the next two years.

The COVID '19 pandemic has become the cause of the global economic recession (Adžić S., Al-Mansour, 2021). It has penetrated into all economic branches and branches. The sectors most directly dependent on customer mobility were most affected. Hazdra (2013) states that according to current statistics, over $60 \%$ of Czechs work in services and this number is constantly growing. In countries west of us, this number is even higher, where more than $70 \%$ work in services. The recession growing into a crisis can also be seen in the cyber environment. Although the cyber crisis is largely unexplored, two comparative analyzes of Estonia 2007 and the United Kingdom 2017 partially concluded that the analysis of cross-border crises, which identified certain differences, identified cases that involved similar prominent crisis management challenges in the performance of tasks. central crisis management (Backman, 2020). The global environment is very closely interconnected, thus creating the preconditions for a global recession and crisis in tourism as well. The potential impact of crisis events on international tourism is likely to increase in size and frequency as tourism becomes increasingly hypermobile (Hall, 2010). A number of scientific studies dealing with theories of European integration have suggested that no single integration theory can be fully responsible for the different policy-making settings of the crises the EU has faced over the past decade (Hooghe, Marks, 2019, Moravcsik, 2018, Niemann, Ioannou, 2015, Schimmelfennig, 2018). The only right way is suggested by Saurugger (2016) in combining theoretical frameworks to understand the complexity of crisis-induced integration.

A crisis situation corresponds to an extraordinary moment of uncertainty, which poses an immediate threat to the proper functioning of a policy area that the crisis in one or more EU Member States calls into question. A crisis situation can be characterized by many features of crisis pressures. One of the major crisis pressures is the political legacy activated by the crisis. The second example of crisis pressure is the asymmetry of the crisis situation of individual EU member states, where individual states are disproportionately affected by the crisis, some more than others (Ferrara, Kriese, 2021).

The current crisis caused by COVID'19 has hit the area of trade business the hardest in the Czech Republic. Thanks to government measures, in March 2021, the activities of approximately 11,000 self-employed persons were suspended, which is an increase of $3 \%$ compared to 2020 . The trade was interrupted by about 44,000 individuals, which is a quarter more than in 2020, 63\% more than in 2019 and $85 \%$ more than in 2018 (Štěpánová, 2021).

Although the country (Czech Republic) is recovering very slowly from pandemic impacts, there are still no consistent proposals for business to rebuild local, separate crises caused by the COVID'19 pandemic in different sectors of the national economy. It can no longer be said that the country is affected by the crisis, but rather a stage of deep uncertainty has arisen for small businesses. There is no crisis scenario, only ad hoc subsidy titles, which are also not well prepared administratively. Thus, even the most prepared institutions and companies are almost close to disaster (Etemad, 2020).

It is necessary to take the present comprehensively with the no less burning problems of globalization, such as: climate, terrorism, other infectious diseases, unregulated cyberspace (cryptocurrency), the proliferation of more destructive weapons, trade, investment. The 
interconnection of these global external indicators of crises has far greater consequences for the entire world economy and business with catastrophic consequences than one current indicator - COVID'19. It is necessary to create a comprehensive vision of the situation in the national sector, and not to solve individual turbulent phenomena. Experience has shown that most of the small and medium-sized business sector was not prepared for a given situation, did not expect a period of restriction or even a ban on its business. After a pandemic, other pressure waves may arise, resulting from global economic and trade approaches, for example in the fields of energy, agriculture (water), climate change (tornadoes), etc. Technological adaptation in online solutions that have made it possible to combine the interests of participants in business models (consumers, suppliers, employees, investors). This has created a gap between those businesses that have followed the traditional strategy and those that have opted for digital transformation or interaction with digital business.

In this crisis situation, the weight of information technology and digitization had a positive effect. In the context of government measures restricting business in various areas of the economy, this has led to the accelerated deployment of digital technologies, especially in the transition to online work, entertainment, shopping, government and education (Kudlac et al., 2017). In connection with the digitization of communication, there has been an interesting experience that leniency positively and significantly affects the level of digitization of the country and above expectations suggests a negative, significant relationship between individualism and the degree of digitization (Rubino et al, 2020).

The COVID'19 pandemic crisis 19 revealed, on the one hand, the inability of a number of SMEs to perform their functions, leading to the instability of competition and the growing impact of the crisis, and encouraging successful solutions through new dynamic strategies using the digital business platform. Slevomat, Mailroom, MS Teams, etc.). This has completely changed the situation in the competitive market, where growing market shares of digital business platforms can be expected. The key factors influencing business in a pandemic crisis are:

1. Availability of resources (energy, raw materials, personnel, technology).

2. A growing wave of anti-globalization sentiments and actions.

3. Analysis of short-term needs in the time frame (addressing uncertainty after the end of the pandemic).

4. Experience in forming new opportunities for business forms.

5. Analysis of competition, especially technology leaders.

6. Transition to digital communication and parallel transition to digital environment.

Ad. 1 The availability of resources in a pandemic crisis is crucial for all businesses. The time has come for a shortage of some global raw materials (coal, gas, oil), which deepens the whole crisis. The Czech Republic and other developed countries do not have enough alternative sources and thus the availability of resources becomes an influential crisis wave. The lack of qualified staff is a significant problem in times of crisis. The crisis always triggers greater job mobility, where workers are looking for employment opportunities in the sector least affected by the crisis and are no longer returning to their jobs after the crisis. This exacerbates the shortage of qualified human resources for the post-crisis period.

Ad. 2 Anti-globalization sentiment and disintegration proposals are beginning to show significantly throughout global society. This may cause another wave of crises, which may lead to the disintegration of integrated economic groupings and completely change the competitive world trade and economy. The disintegration of established economic networks would be a step backwards, causing economic, economic and cultural conflicts associated with the demands of individual states for their global shares. 
Ad. 3 An analysis of short-term needs over time is needed to avoid making money on uncertainties when postponing needs to a future. Inducing delayed acquisitions at lower costs or slowing down sales in the hope of higher prices (rising inflation) trigger unjustified measures during corporate crises, which will increase the cash gap and lead to the likelihood of their bankruptcy. The slowing pandemic crisis is leading to overpricing of products and services associated with the biased economic behavior of world economic policy leaders, and thus another crisis wave is emerging for society in the form of inflationary progression.

Ad. 4 The experience gained during the crisis can be an inspiration for business organizations in that they can be much more prepared for the next possible crisis wave or even a crisis. For example, a significant number of organizations have gained positive experience with the introduction of a home office.

Ad. 5 Technology leaders tend to control supply and create artificial deficiencies to raise prices and thus affect their position in a competitive market. In times of crisis, consumers are forced to agree to a price increase in order to have access to basic products and services. In a global environment, prices are used as the main tool to stimulate demand, provided that there is a highly competitive environment and high demand flexibility. However, technology leaders behave in such a way that they manipulate prices by their monopoly power due to the brand or quality of products, while they need to compete in a hypercompetitive environment with other competitors offering similar offers (Chen M.R., 2010). Welter and Smallbone (2011) also draw attention to market knowledge, especially for small businesses, which emphasizes the great weight of market analysis and the ability to predict the competitive situation.

Ad. 6 The importance of information and quality communication is key to the current estimation of uncertainty and the impact of crises. Almost all new advances in management and production, including additive technologies, rely heavily on information (Hannibal, 2020). The availability of reliable sources of information is becoming a means of reducing uncertainty, especially as regards rapid responses to anti-crisis management.

\subsection{Digitization of society - an important factor in reducing uncertainties and crisis waves}

The digitization of society is a sufficient starting point for resolving crisis situations in order to mitigate the effects of crisis waves on the population. In general, the Czech Republic is still lagging behind in digitization behind countries that have taken the digital environment as a parallel to the lifestyle of society (Estonia, Denmark, Great Britain, Germany) very seriously. The availability of information has become key to modern and effective decisionmaking in matters that affect not only the business community, but also society as a whole. Digitization has become a naturally evolving reality in developed countries and is, in many cases, taken for granted. At the same time, the Czech Republic still lacks the authority to support the entire digitization process, and even in the ranking of digital maturity, the Czech Republic dropped to 28th place in 2020 (Global Connectivity Index, Huawei). This was clearly reflected in the solution of the pandemic crisis situation. Information about the crisis came to society in various ways, evoking a sense of helplessness in society. Although the Czech Republic is very good in the area of high-speed internet connection, for which we can thank the mobile and fixed operators, there is a lack of investment in modern technologies that would increase the use of very good connectivity. The Czech Republic is not an advanced destination in digital literacy either. Although the COVID'19 pandemic forced many 
companies and people to use the online environment more intensively, the digital literacy of the population did not improve, according to expert experts. A large part of people in society cannot search for and especially evaluate information. In 2019, at the time of the onset of the pandemic crisis, $30 \%$ of people in the Czech Republic did not have basic digital skills (Eurostat, 2019). This situation did not improve even in 2020 and 2021. There are still 5\% of people in the Czech Republic completely digitally illiterate. Although the majority of the population of the Czech Republic believes that it is very well equipped digitally, business organizations say the opposite. New employees are therefore motivated to learn in new forms and tools of digital communication and to pay more attention to the overall digital environment.

According to partial surveys in specific companies, employees claim that they can work, for example, in the Excel environment, but they are no longer able to use this platform to solve more complex tasks. Great hopes are now placed in the Czech Republic in the younger generations, which are surrounded by a digital environment and there is a chance to improve digital literacy. For example, Generation Z, which is introduced by young people born after 1995. Their lifestyles are social networks, their world is determined by the digital environment and mobile connections. They are not interested in politics, they postpone the family, deal with depression, anorexia, self-harm and are constantly worried that they will not be able to cope with the demands placed on them by modern society and are afraid that they belong nowhere and are constantly trying to get out of hopeless situations. is life got. Generation $\mathrm{Z}$ is a clear impact of the global lifestyle and the result of raising single-parent or dysfunctional families. It's called the "damn generation $Z$ ". The vast majority of representatives of the $Z$ generation do not recognize any authority and resort to the virtual world of social networks. Their digital literacy is better than previous generations $\mathrm{Y}$ and $\mathrm{X}$, because they are surrounded by digital technologies from birth. They have been able to use various communication devices and technologies since childhood; they do not know the world without the Internet. Generation $\mathrm{Z}$ grows gradually with the development of technology, so they should have no problem working with them. Prensky (2001) describes this generation as digital natives and generations $\mathrm{Y}$ and $\mathrm{X}$ as digital immigrants.

Although Generation $\mathrm{Z}$ is expected to embrace new technologies without difficulty, practice shows that Generation $Z$ is not driven to use technology evenly and to use all the information it needs. Gui et al. (2017) consider it a new digital skill. Generation $Z$ is a problem for business organizations because it changes established employment practices. It is very difficult to raise a loyal employee from them; they change their job positions according to their criteria. In the current era of turbulent crisis-creating phenomena, Generation $\mathrm{Z}$ is growing up in a rapidly changing environment affected by the digitization of real-life processes, and it is necessary to assess when technology thrives and when it damages or in other words. banal information and communication noises.

The global crisis caused by the COVID' 19 pandemic 19 represents, on the one hand, major changes in the global economic area, which are associated with the measures of individual integration groups and individual governments, and can contribute to the spread of new modern business and communication methods in the digital environment. The most vulnerable group are young people in generation $\mathrm{Z}$, who are already showing symptoms of higher vulnerability in cases of dysfunctional global network processes. Although closely linked to the digital environment and an internet parallel to their lifestyle, they can be expected to be the first to suffer from mental disorders such as frustration, depression, insomnia, anxiety in the context of a pandemic, and in particular to a lower level of general education thanks to an imperfect system of online teaching. The only chance to help this generation is to create an interactive educational space in digital form, which should be motivating for the young generation learning to understand the causes and effects of various crisis waves and focus on their solutions. It can be expected that after the end of the pandemic, 
the quality readiness of young workers and organizations will be decisive, and without digitizing the necessary processes it is very difficult to realize.

\section{Conclusions}

Crisis are part of the general economic cycle. They cannot be understood only as a threat, a danger, but also as an opportunity. Crisis arise for various reasons, they are the culmination of turbulent phenomena in social and economic life in the form of crisis waves. Globalization has brought a lot of positive, but also quite negative. It strongly influenced demographic changes and brought negative migration waves. It helped the economic rise of the new powers and caused the decline of international institutions. It has caused the uncontrolled use of energy resources and the already unquestionable climate change. Thanks to the great development of technology and the digital information platform, space has been created for access to the information center and to new opportunities for business activities that have penetrated into all areas of life. The pandemic crisis caused by COVID'19 has completely confirmed the unpreparedness of global society for its solution. No country has a functioning early warning system and alternative strategies to address this crisis. Only those business organizations that have drawn a parallel business in the digital environment have survived this period, others that have remained with established strategies now feel existential problems. It was the digitization of various sales and communication processes that was one of the most developed procedures that enabled organizations to sustain themselves economically. In the field of digital literacy, there is hope that the young generation $\mathrm{Z}$ will start using information technology more pragmatically for their growth and self-realization, and will not only focus on social media and information noise. Although this Generation $\mathrm{Z}$ is one of the most vulnerable groups in the COVID'19 pandemic crisis, with sophisticated leadership and digital skills training, it is possible for them to learn to better manage and deal with the next crisis.

\section{Acknowledgements}

This paper is an output of the science project student's specific research No. 7429/2020/06 University of Finance and Administration Prague under the title Media Behaviour of the Generation Z.

\section{References}

1. Adžić, S., \& Al-mansour, J. (2021) Business analysis in the times of COVID-19: Empirical testing of the contemporary academic findings. Management Science Letters.

2. Backman, S. (2020) Conceptualizing cyber crises. Journal of Contingencies and Crisic management.

3. Etemad, H. (2020). Managing uncertain consequences of a global crisis: SMEs encountering adversities, losses, and new opportunities. Journal of International Entrepreneurship, 18(2), 125-144 
4. Ferrara, F. M., \& Kriesi, H. (2021). Crisis Pressures and European Integration. Journal of European Public Policy, September 2, 2021, 1-23.

5. Gui, M., Fasoli, M., \& Carradore, R. (2017). "Digital Well-Being”. Developing a New Theoretical Tool For Media Literacy Research. Italian Journal of Sociology of Education, 9(1), 155-173.

6. Hall, C. M. (2010) Crisis events in tourism: Subject of crisis in tourism. Current Issues in Tourism, 13(5).

7. Hannibal, M. (2020). The influence of additive manufacturing on early internationalization: considerations into potential avenues of IE research. Journal of International Entrepreneurship, 18(4), 473-491

8. Hooghe, L., \& Marks, G. (2019). Grand theories of European integration in the twentyfirst century. Journal of European Public Policy, 26(8), 1113-1133.

9. Chen, M.-J., Lin, H.-C. \& Michel, J. G. (2010). Navigating in a hypercompetitive environment: the roles of action aggressiveness and TMT integration. Strategic Management Journal, 31(13), 1410-1430.

10. Kudlac, S., Majercak, J., \& Majercak, P. (2017). Comparison of different variants of logistics chain with the use of air transport using the software application. In Proceedings of 6th International Conference on Air Transport (INAIR) (pp. 45-50).

11. Moravcsik, A. (2018). Preferences, power and institutions in 21st-century Europe. Journal of Common Market Studies, 56(7), 1648-1674.

12. Niemann, A., \& Ioannou, D. (2015). European economic integration in times of crisis: A case of neofunctionalism? Journal of European Public Policy, 22(2), 196-218.

13. Prensky, M. (2001). Digital Natives, Digital Immigrants. On the Horizon, 9(5). http://www.marcprensky.com/writing/Prensky\%20-20

Digital\%20Natives, \%20Digital\%20Immigrants\%20-\%20Part1.pdf

14. Rubino, M., Vitolla, F., Raimo, N. and Garcia-Sanchez, I.-M. (2020). "Cross-country differences in European firms' digitalisation: the role of national culture", Management Decision, 58(8), 1563-1583.

15. Saurugger, S. (2016). Politicisation and integration through law: Whither integration theory? West European Politics, 39(5), 933-952.

16. Schimmelfennig, F. (2018). European integration (theory) in times of crisis. A comparison of the euro and Schengen crises. Journal of European Public Policy, 25(7), 969-989.

17. Štěpánová, P. (2021). V prvním čtvrtletí podnikání přerušilo 43667 živnostníků, o $23 \%$ víc než loni. Dun \& Bradstreet [online]. Praha: Bisnode Česká republika, 28.04.2021 https://www-prod.dnb.com/cs-cz/o-bisnode/o-nas/novinky/v-prvnim-ctvrtletipodnikani-prerusilo-43667-zivnostniku-o-23-procent-vic-nez-loni/

18. Welter, F., \& Smallbone, D. (2011). Institutional Perspectives on Entrepreneurial Behavior in Challenging Environments. Journal of Small Business Management, 49(1), 107-125 